\title{
Pengaruh Senam Lansia Terhadap Perubahan Tekanan Darah Pada Lansia Dengan Hipertensi di Wilayah Kp. Dukuh II dan Dukuh III Kramat Jati Jakarta Timur
}

\author{
"Sundari Fatimah"1), Febi Puji Utami ${ }^{2)}$
}

Program Studi S1 Kebidanan, Fakultas Kesehatan, Universitas Mohammad Husni Thamrin

Corresponden author: fatimahsundari94@gmail.com

Received : 29 Desember $2020 \quad$ Accepted : 6 September $2021 \quad$ Published: 30 September 2021

DOI: https://doi.org/10.37012/jik.v13i2.433

\begin{abstract}
ABSTRAK
Terdapat beberapa macam penyakit yang biasa menimpa para lansia antara lain hipertensi, jatung koroner, stroke, dan lain sebagainya. Prevalensi kejadian hipertensi sangat tinggi pada lansia, yaitu 60\%$80 \%$ pada usia diatas 65 tahun. Tujuan penelitian ini untuk menganalisis Pengaruh Senam Lansia Terhadap Perubahan Tekanan Darah Pada Lansia Dengan Hipertensi di Wilayah KP. Dukuh II dan Dukuh III Kramat Jati Jakarta Timur. Penelitian ini menggunakan pendekatan kuantitatif, dengan metode quasy eksperiment. Responden dalam penelitian ini adalah lansia yang mengalami hipertensi, dengan Teknik sampling Total Population. Hasil penelitian dianalisis dengan Uji T sampel berpasangan dan menunjukkan (1) Tekanan darah responden sebelum dilakukan senam lansia yaitu nilai mean sistolik 165,00 $\mathrm{mmHg}$ dan mean diastolik $111,25 \mathrm{mmHg}$, (2) Tekanan darah responden sesudah dilakukan senam lansia yaitu nilai mean sistolik 146,25 $\mathrm{mmHg}$ dan mean diastolik 98,13 $\mathrm{mmHg}$, (3) Ada pengaruh senam lansia terhadap perubahan tekanan darah pada lansia penderita hipertensi dengan selisih sistolik $18,750 \mathrm{mmHg}$ dan selisih diastolik 13,125 mmHg. Kesimpulan bahwa kelompok intervensi yang diberikan senam lansia mengalami penurunan hipertensi dibandingkan kelompok kontrol yang tidak diberikan senam lansia. Diharapkan hasil penelitian dapat digunakan sebagai informasi kepada lansia agar dapat melakukan senam lansia secara rutin untuk membantu mengontrol tekanan darah.
\end{abstract}

Kata Kunci: Senam Lansia, Hipertensi, Tekanan Darah, Lansia.

\section{ABSTRACT}

There are several types of diseases that commonly afflict the elderly, including hypertension, coronary heart disease, stroke, and so on. The prevalence of hypertension is very high in the elderly, namely $60 \%$ $-80 \%$ at the age above 65 years. The purpose of this study was to analyze the effect of gymnastics for the elderly on changes in blood pressure in the elderly with hypertension in the KP area. Dukuh II) and Dukuh III Kramat Jati, East Jakarta. This research uses a quantitative approach, with method quasy experiment. Respondents in this study were elderly people with hypertension, with the sampling technique Total Population. The results of the study were analyzed using paired sample T test and showed (1) The blood pressure of the respondent before elderly exercise was the mean systolic 165.00 $\mathrm{mmHg}$ and the mean diastolic $111.25 \mathrm{mmHg}$, (2) The respondent's blood pressure after elderly exercise was the mean systolic $146.25 \mathrm{mmHg}$ and a mean diastolic $98.13 \mathrm{mmHg}$, (3) There is an effect of elderly exercise on changes in blood pressure in elderly people with hypertension with a systolic difference $18.750 \mathrm{mmHg}$ and a diastolic difference $13.125 \mathrm{mmHg}$. Concluded that the intervention group that was given elderly exercise experienced a decrease in hypertension compared to the control group who was not given elderly exercise. It is hoped that the results of study can be used as information for the elderly so that they can do elderly exercise regularly to help control blood pressure.

Keywords: Elderly Gymnastics, Hypertension, Blood Pressure, Elderly. 


\section{PENDAHULUAN}

Ada beberapa perubahan fisik pada lansia yang dapat menjadi suatu kondisi lansia terserang penyakit, seperti perubahan kardiovaskuler. Terdapat beberapa macam penyakit yang biasa menimpa para lansia antara lain hipertensi, diabetes mellitus, jatung koroner, stroke, katarak, dan lain sebagainya. Macam-macam masalah kesehatan tersebut yang sering menimpa lansia yaitu hipertensi yang bisa menjadi awitan dari berbagai masalah kardiovaskuler lainnya yang lebih gawat (Setiawan GW, 2013).

Prevalensi kejadian hipertensi sangat tinggi pada lansia, yaitu 60\%-80\% pada usia $>65$ tahun. Tidak sedikit orang menganggap penyakit hipertensi pada lansia adalah hal biasa. Sehingga mayoritas masyarakat menganggap remeh penyakit ini. Hipertensi dapat menyebabkan berbagai macam komplikasi antara lain gagal jantung dan stroke (Muhamad A, 2012).

Bukti yang ada menunjukkan bahwa latihan olah raga pada usia lanjut dapat mencegah kehilangan fungsional, bahkan latihan yang teratur dapat mengurangi morbiditas dan mortalitas yang diakibatkan oleh penyakit kardiovaskuler. Penelitian yang telah dilakukan di Jepang memberikan salah satu bukti bahwa olahraga yang mudah dan teratur seperti senam sangat efektif untuk menurunkan tekanan darah (Williams L, 2001).

Banyaknya kejadian Hipertensi pada Lansia, maka perlu diketahui apakah senam lansia berpengaruh pada perubahan tekanan darah pada lansia dengan hipertensi. Berdasarkan observasi dan survei pendahuluan yang dilakukan peneliti pada tanggal 20 Oktober 2020 di Wilayah KP. Dukuh II (RT 05/RW 01) dan Dukuh III (RT 04/RW 02) Kramat Jati Jakarta Timur, pada bulan Januari 2020 sampai September 2020 terdapat 120 orang lansia di kedua RT tersebut. Menurut data pemeriksaan tekanan darah yang dilakukan peneliti pada beberapa lansia, didapatkan hasil pemeriksaan dimana rata-rata tekanan darahnya tinggi atau mengalami Hipertensi sebanyak 64 lansia.

Dari hasil uraian diatas, maka peneliti tertarik untuk menganalisis pengaruh senam lansia terhadap perubahan tekanan darah pada lansia dengan hipertensi di Wilayah KP. Dukuh II (RT 05/RW 01) dan Dukuh III (RT 04/RW 02) Kramat Jati Jakarta Timur.

\section{METODE}

Penelitian ini menggunakan pendekatan kuantitatif, dan Metode yang digunakan dalam penelitian ini adalah quasy eksperiment atau eksperimen semu. Responden dalam penelitian ini adalah lansia yang mengalami hipertensi di Wilayah KP. Dukuh II (RT 05/RW 01) dan Dukuh III (RT 04/RW 02) Kramat Jati Jakarta Timur. Teknik sampling yang dipilih oleh peneliti dalam penelitian ini adalah Total Population. 
Tahap penelitian adalah tahap (1) mengambil data penelitian dengan data primer Lansia atau observasi secara langsung di Wilayah KP. Dukuh II (RT 05/RW 01) dan Dukuh III (RT 04/ RW 02) Kramat Jati Jakarta Timur, tahap (2) kegiatan penelitian dengan melakukan senam lansia pada lansia dengan hipertensi di kedua wilayah tersebut, tahap (3) analisis data. Data yang dikumpulkan meliputi data primer menggunakan lembar observasi dan hasil penelitian dianalisis dengan Uji T sampel berpasangan. Teknik analisis yang digunakan yaitu analisis univariat, dan bivariat. Sebelum dilakukan analisis bivariat, terlebih dahulu dilakukan uji normalitas. Uji normalitas yang digunakan adalah Shapiro Wilk. Dengan uji Statistik paired ttest. Penggunaan uji paired t-test bertujuan untuk mengetahui perubahan tekanan darah sebelum dan sesudah dilakukan senam lansia. Sedangkan untuk uji parametrik menggunakan uji tberpasangan, namun jika distribusi tidak normal menggunakan uji Wilcoxon dengan taraf kesalahan 5\% (Sugiyono, 2010).

\section{HASIL DAN PEMBAHASAN}

\section{Hasil}

Tabel 1.

Distribusi Frekuensi Karakteristik Responden Berdasarkan Usia, Pendidikan, dan Pekerjaan

\begin{tabular}{|c|c|c|c|c|}
\hline \multirow[b]{2}{*}{ Karakteristik } & \multicolumn{2}{|c|}{ Kelompok Intervensi } & \multicolumn{2}{|c|}{ Kelompok Kontrol } \\
\hline & Frekuensi & $\begin{array}{c}\text { Presentase } \\
(\%)\end{array}$ & Frekuensi & $\begin{array}{c}\text { Presentase } \\
(\%)\end{array}$ \\
\hline \multicolumn{5}{|l|}{ Usia: } \\
\hline 60 - 74 Tahun & 10 & 62,6 & 11 & 68,7 \\
\hline 75 - 90 Tahun & 3 & 18,7 & 2 & 12,6 \\
\hline$>90$ Tahun & 3 & 18,7 & 3 & 18,7 \\
\hline \multicolumn{5}{|l|}{ Pendidikan: } \\
\hline Dasar (SD, SMP) & 11 & 68,7 & 9 & 56,2 \\
\hline Menengah (SMA) & 3 & 18,7 & 6 & 37,6 \\
\hline Perguruan Tinggi & 2 & 12,6 & 1 & 6,2 \\
\hline \multicolumn{5}{|l|}{ Pekerjaan: } \\
\hline Ibu Rumah Tangga & 8 & 50,0 & 10 & 62,6 \\
\hline PNS & 1 & 6,2 & 1 & 6,2 \\
\hline Swasta & 2 & 12,6 & 1 & 6,2 \\
\hline Wiraswasta & 5 & 31,2 & 4 & 25,0 \\
\hline Jumlah & 16 & $100 \%$ & 16 & $100 \%$ \\
\hline
\end{tabular}

Tabel 1 pada karakteristik responden berdasarkan usia dapat diinterpretasikan bahwa sebagian besar dari kelompok intervensi yaitu $10(62,6 \%)$ berusia 60-74 tahun dan sebagian besar dari kelompok kontrol yaitu 11 (68,7\%) berusia antara 60-74 Tahun. 1 Sedangkan pada karakteristik responden berdasarkan pendidikan dapat diinterpretasikan bahwa sebagian besar dari kelompok intervensi yaitu $11(68,7 \%)$ berpendidikan Dasar (SD, SMP) dan sebagian besar dari kelompok kontrol yaitu 9 (56,2\%) berpendidikan Dasar (SD, SMP). Lalu pada karakteristik responden 
berdasarkan pekerjaan dapat diinterpretasikan bahwa setengah dari kelompok intervensi yaitu 8 (50,0\%) dengan status Ibu Rumah Tangga dan sebagian besar dari kelompok kontrol yaitu 10 $(62,6 \%)$ dengan status Ibu Rumah Tangga.

Tabel 2.

Distribusi Frekuensi Karakteristik Responden Berdasarkan Tekanan Darah Sistolik dan Diastolik

Kelompok Intervensi Sebelum dan Sesudah Diberikan Senam Lansia Dengan Hipertensi

\begin{tabular}{|c|c|c|c|c|c|c|c|}
\hline Variabel & $\mathbf{N}$ & Mean & Median & Mode & SD & Max & Min \\
\hline $\begin{array}{l}\text { Tekanan Darah Sistolik } \\
\text { Sebelum Perlakuan }\end{array}$ & 16 & 165,00 & 165,00 & 160 & 8,944 & 180 & 150 \\
\hline $\begin{array}{l}\text { Tekanan Darah Sistolik } \\
\text { Sesudah Perlakuan }\end{array}$ & 16 & 146,25 & 145,00 & 140 & 10,878 & 170 & 130 \\
\hline $\begin{array}{l}\text { Tekanan Darah Diastolik } \\
\text { Sebelum Perlakuan } \\
\text { Tekanan Darah Diastolik }\end{array}$ & 16 & 111,25 & 110,00 & 120 & 11,475 & 130 & 90 \\
\hline $\begin{array}{l}\text { Tekanan Darah Diastolik } \\
\text { Sesudah Perlakuan }\end{array}$ & 16 & 98,13 & 95,00 & 90 & 13,769 & 120 & 80 \\
\hline
\end{tabular}

Tabel 2 dapat dijelaskan bahwa dari 16 responden, tekanan darah sistolik sebelum diberikan senam lansia memiliki mean $165,00 \mathrm{mmHg}$ dan median $165,00 \mathrm{mmHg}$ dengan hasil tes uji normalitas $\rho$-value $=0,064$. Sedangkan, tekanan darah sistolik sesudah diberikan senam lansia memiliki mean 146,25 mmHg dan median 145,00 $\mathrm{mmHg}$ dengan hasil tes uji normalitas $\rho$-value $=0,145$. Lalu dari 16 responden, tekanan darah diastolik sebelum diberikan senam lansia memiliki mean $111,25 \mathrm{mmHg}$ dan median $110,00 \mathrm{mmHg}$ dengan hasil tes uji normalitas $\rho$-value $=0,069$. Sedangkan, tekanan darah diastolik sesudah diberikan senam lansia memiliki mean 98,13 mmHg dan median 95,00 mmHg dengan hasil tes uji normalitas $\rho$-value=0,074.

Tabel 3.

Distribusi Frekuensi Karakteristik Responden Berdasarkan Tekanan Darah Sistolik dan Diastolik Kelompok Kontrol Pre Test dan Post Test Pada Lansia Dengan Hipertensi

\begin{tabular}{|cccccccc}
\hline \multicolumn{1}{c}{ Variabel } & N & Mean & Median & Mode & SD & Max & Min \\
\cline { 2 - 8 } Tekanan Darah Sistolik Pre Test & 16 & 155,63 & 150,00 & 150 & 10,935 & 180 & 140 \\
\hline Tekanan Darah Sistolik Post Test & 16 & 156,88 & 155,00 & 150 & 11,383 & 180 & 140 \\
\hline Tekanan Darah Diastolik Pre Test & 16 & 103,75 & 100,00 & 100 & 9,574 & 120 & 90 \\
\hline Tekanan Darah Diastolik Pre Test & 16 & 105,00 & 105,00 & 100 & 8,944 & 120 & 90 \\
\hline
\end{tabular}

Tabel 3 dapat dijelaskan bahwa dari 16 responden, tekanan darah sistolik Pre Test memiliki mean 155,63 mmHg dan median 150,00 mmHg dengan hasi tes uji normalitas $\rho$ value $=0,073$. Sedangkan, tekanan darah sistolik Post Test memiliki mean 156,88 mmHg dan median 155,00 mmHg dengan hasi tes uji normalitas $\rho$-value $=0,161$. Lalu dari 16 responden, 
tekanan darah diastolik Pre Test memiliki mean 103,75 mmHg dan median 100,00 mmHg dengan hasi tes uji normalitas $\rho$-value $=0,065$. Sedangkan, tekanan darah diastolik Post Test memiliki mean 105,00 $\mathrm{mmHg}$ dan median $105,00 \mathrm{mmHg}$ dengan hasi tes uji normalitas $\rho$ value $=0,064$.

Pada uji normalitas Kelompok Intervensi dan Kelompok Kontrol Shapiro Wilk dapat disimpulkan $\mathrm{p}$ value $>\alpha$ dengan $\alpha=0,05$. Sehingga, sebaran data normal dan dapat digunakan uji parametrik dengan uji t sampel berpasangan.

Tabel 4.

Perbandingan Tekanan Darah Sistolik dan Diastolik Sebelum dan Sesudah Dilakukan Senam Lansia

\begin{tabular}{llcc}
\hline \multicolumn{1}{c}{ Variabel } & Mean & SD & SE \\
\hline Tekanan Darah Sistolik Sebelum & 165,00 & 8,944 & 2,236 \\
Tekanan Darah Sistolik Sesudah & 146,25 & 10,878 & 2,720 \\
Tekanan Darah Diastolik Sebelum & 111,25 & 11,475 & 2,869 \\
Tekanan Darah Diastolik Sesudah & 98,13 & 13,769 & 3,442 \\
\hline P value $=0,000 \quad \alpha=0,05$ & & & \\
P value $=0,004 \quad \alpha=0,05$ & & & \\
\hline
\end{tabular}

Pada Tabel 4 diinterpretasikan mean tekanan darah sistolik terdapat penurunan $18,750 \mathrm{mmHg}$ antara sebelum dilakukan senam lansia sebesar $165,00 \mathrm{mmHg}$ dengan sesudah dilakukan senam lansia sebesar $145,25 \mathrm{mmHg}$. Dari sini dapat dilihat adanya perbedaan tekanan darah sistolik sebelum dan sesudah dilakukan senam lansia.

Hasil uji T sampel berpasangan menunjukkan angka signifikansi sebesar 0,000 yang artinya kurang dari $\alpha=0,05$, dan analisis thitung sebesar 9,303 yang lebih besar dari t tabel untuk df $=15$ adalah 2,131 dengan demikian maka $\mathrm{H}_{0}$ ditolak berarti ada pengaruh senam lansia terhadap perubahan tekanan darah sistolik pada lansia di Wilayah KP. Dukuh III (RT 04/RW 02) Kramat Jati Jakarta Timur.

Sedangkan mean tekanan darah diastolik terdapat penurunan $13,125 \mathrm{mmHg}$ antara sebelum dilakukan senam lansia sebesar $111,25 \mathrm{mmHg}$ dengan sesudah dilakukan senam lansia sebesar 98,13. Dari sini dapat dilihat adanya perbedaan tekanan darah diastolik sebelum dan sesudah dilakukan senam lansia.

Hasil uji T sampel berpasangan menunjukkan angka signifikansi sebesar 0,004 yang artinya kurang dari $\alpha=0,05$, dan hasil analisis t hitung sebesar 3,416 yang lebih besar dari t tabel untuk df = 15 adalah 2,131 dengan demikian maka $\mathrm{H}_{0}$ ditolak berarti ada pengaruh senam lansia terhadap perubahan tekanan darah diastolik pada lansia di Wilayah KP. Dukuh III (RT 04/RW 02) Kramat Jati Jakarta Timur. 
Tabel 5.

Perbandingan Tekanan Darah Sistolik dan Diastolik

Kelompok Kontrol Pre Test dan Post Test Pada Lansia

\begin{tabular}{lccc}
\hline \multicolumn{1}{c}{ Variabel } & Mean & SD & SE \\
\hline Tekanan Darah Sistolik Pre Test & 155,63 & 10,935 & 2,734 \\
Tekanan Darah Sistolik Post Test & 156,88 & 11,383 & 2,846 \\
Tekanan Darah Diastolik Pre Test & 103,75 & 9,574 & 2,394 \\
Tekanan Darah Diastolik Post Test & 105,00 & 8,944 & 2,236 \\
\hline P value $=0,333 \quad \alpha=0,05$ & & \\
\hline
\end{tabular}

Pada tabel 5 diinterpretasikan memiliki persamaan kenaikan mean tekanan darah sistolik maupun diastolik sebesar 1,250 $\mathrm{mmHg}$. Dari sini dapat dilihat adanya perbedaan tekanan darah sistolik maupun diastolik Pre Test dan Post Test.

Hasil uji T sampel berpasangan pada kelompok kontrol pre test dan post test menunjukkan angka signifikansi sebesar 0,333 yang artinya lebih dari $\alpha=0,05$ dan hasil analisis t hitung sebesar -1,000 yang lebih kecil dari t tabel untuk df $=15$ adalah 2,131 dengan demikian maka $\mathrm{H}_{1}$ ditolak berarti tidak ada pengaruh perubahan tekanan darah pada lansia di Wilayah KP. Dukuh II (RT 05/RW 01) Kramat Jati Jakarta Timur.

\section{Pembahasan}

Pada penelitian ini tekanan darah pada lansia sebelum dilakukan senam lansia tergolong hipertensi stadium 2. Peneliti berpendapat bahwa faktor yang mempengaruhi peningkatan tekanan darah adalah genetik, umur, jenis kelamin, obesitas, gaya hidup, dan asupan (Constantinides P, 1994). Senam Lansia merupakan salah satu terapi komplementer untuk menurunkan tekanan darah, baik sistolik maupun diastolik.

Senam lansia yang merupakan salah satu solusi untuk membuat tekanan darah tetap terjaga, karena peredarah darah akan lancar dan meningkatkan jumlah volume darah. Selain itu 20\% darah terdapat di otak, sehingga akan terjadi proses indorfin hingga terbentuk hormon norepinefrin yang dapat menimbulkan rasa gembira, rasa sakit hilang, adiksi (kecanduan gerak) dan menghilangkan depresi (WHO, 1989). Dengan mengikuti senam lansia efek minimalnya adalah lansia merasa berbahagia, senantiasa bergembira, bisa tidur lebih nyenyak, pikiran tetap segar, dan dapat dijadikan sebagai terapi pada lansia dengan hipertensi untuk mengontrol tekanan darahnya agar tidak terlalu tinggi atau tetap terjaga (Nugroho, 2008).

Jadi, penting bagi para lansia yang menderita hipertensi untuk melakukan senam lansia, disamping memiliki dampak positif terhadap peningkatan fungsi organ tubuh juga berpengaruh dalam meningkatkan imunitas dalam tubuh manusia setelah latihan teratur. Tingkat kebugaran dievaluasi dengan mengawasi kecepatan denyut jantung waktu istirahat yaitu kecepatan denyut 
nadi sewaktu istirahat. Jadi supaya lebih bugar, kecepatan denyut jantung sewaktu istirahat harus menurun (James, 2008).

Senam Lansia dilakukan selama $2 x$ seminggu secara berkelanjutan agar hasil yang ingin dicapai bisa lebih maksimal. Setelah diberikan senam lansia, sebagian besar responden mengalami penurunan tekanan darah (Smeltzer, 2001).

Hasil penelitian ini menunjukkan adanya penurunan tekanan darah pada sebagian besar responden, namun ada satu responden yang tekanan darahnya tetap. Pada sebagian besar responden yang mengalami penurunan dikarenakan melakukan senam lansia secara rutin. Namun pada responden yang tidak mengalami perubahan tekanan darah dapat disebabkan oleh beberapa faktor resiko lain.

Dari data di atas dapat ditarik kesimpulan bahwa kelompok intervensi yang diberikan senam lansia mengalami penurunan hipertensi dibandingkan kelompok kontrol yang tidak diberikan senam lansia. Hal ini disebabkan pada kelompok intervensi yang diberikan perlakuan senam lansia sedangkan pada kelompok kontrol tidak diberikan perlakuan dan tidak menghindari faktor pemicu.

\section{SIMPULAN DAN REKOMENDASI}

Berdasarkan hasil penelitian dan uraian pada pembahasan, maka dapat diambil kesimpulan bahwa tekanan darah responden sebelum dilakukan senam lansia yaitu nilai mean sistolik sebesar 165,00 mmHg dan mean diastolik sebesar 111,25 mmHg. Sedangkan tekanan darah responden sesudah dilakukan senam lansia yaitu nilai mean sistolik sebesar 146,25 mmHg dan mean diastolik sebesar 98,13 mmHg. Sehingga ada pengaruh senam lansia terhadap perubahan tekanan darah pada lansia penderita hipertensi dengan selisih sistolik sebesar 18,750 $\mathrm{mmHg}$ dan selisih diastolik sebesar 13,125 mmHg di Wilayah KP. Dukuh III (RT 04/RW 02) Kramat Jati Jakarta Timur.

Diharapkan hasil penelitian ini dapat digunakan sebagai informasi untuk lansia agar dapat melakukan senam lansia secara rutin untuk membantu mengontrol tekanan darah pada lansia sehingga dapat mengurangi angka kematian yang disebabkan oleh hipertensi.

\section{REFERENSI}

1. Setiawan GW., Wungouw HIS., Pangemanan DHC. (2013). Pengaruh Senam Bugar Lanju Usia (Lansia) Terhadap Kualitas Hidup Penderita Hipertensi. J Fakultas Kedokteran Universitas Sam Ratulangi Manado, 1, 760-764. 
2. Muhamad, Ardiansyah. (2012). Medikal Bedah Untuk Mahasiswa DIV. Yogyakarta: A Press.

3. Williams L, Wilkins. (2001, Jan, 9). Effects of Exercise Training on Home Blood Pressure Values in Older Adults: a Randomized Controlled Trial. Jurnal of Hypertension. 1, 1045-1052.

4. Departemen Kesehatan, RI. (1999). Pedoman Pembinaan Kesehatan Jiwa Usia Lanjut Bagi Petugas Kesehatan Jakarta: Depkes RI.

5. Constantinides P. (1994). In General Pathobiology, Appleton \& Lange.

6. World Health Organization, (1989). Batasan Lanjut Usia, USA.

7. Nugroho., Wahyudi. (2008). Keperawatan Gerontik dan Geriatrik (Edisi 3). Jakarta: EGC.

8. James., Joyce dkk. (2008). Prinsip - Prinsip Sains Untuk Keperawatan. Jakarta: Erlangga.

9. Smeltzer., Bare. (2001). Buku Ajar Keperawatan Medikal Bedah (Edisi 8 Vol 2). Jakarta: EGC.

10. Kozier. (2010). Buku Ajar Fundamental Keperawatan. Jakarta: EGC.

11. Potter P.A., Perry A. G. (2005). Buku Ajar Fundamental Keperawatan :Konsep, Proses, dan Praktek (Edisi 4 Vol 1). Jakarta: EGC.

12. World Health Organization. (1991). Pendekatan Primary Prevention of Essential Hypertension Report Of a WHO Scientific Group. Geneva: Switzerland.

13. Herlambang. (2013). Menaklukan Hipertensi dan Diabetes. Jakarta Selatan: Tugu Publisher.

14. Elizabeth., J. Corwin. (2009). Buku Saku Patofisiologi. Jakarta: EGC

15. Arif, M. (2009). Pengantar Asuhan Keperawatan Klien Dengan Gangguan Sistem Kardiovaskuler. Jakarta: Salemba Medika.

16. Kemenkes. (2016, Oct, 9). Masalah Hipertensi Di Indonesia. Diakses dari http://www.depkes.go.id/article/view/1909/masalah-hipertensi-di-indonesia.html.

17. Kusmana, D. (2006). Olahraga Untuk Orang Sehat dan Penderita Penyakit Jantung Trias Sok \& Senam 10 Menit (Edisi 2). Jakarta: Fakultas Kedokteran Universitas Indonesia. 
18. Suroto. (2004). Buku Pegangan Kuliah Pengertian Senam, Manfaat Senam dan Urutan Gerakan. Semarang: Unit Pelaksana Teknis Mata Kuliah Umum Olahraga Undip.

19. Departemen Kesehatan, RI. (2003). Pedoman Pengelolaan Kegiatan Kesehatan di Kelompok Lanjut Usia. Jakarta: Depkes RI.

20. Sumintarsih. (2006). Kebugaran Jasmani Untuk Lansia. Olahraga, 147-160.

21. Kelley GA., Kristi AK., Zung VT. (2001). Aerobic Exercise and Resting Blood Pressure : a Meta Analytic Review of Randomized, Controlled Trials. Prev Cardiol, $4(2), 73-80$

22. Fagard RH. (2001). Exercise Characteristics and The Blood Pressure Response to Dynamic Physical Training. Med Sci Sports Exerc, 33(6), 484-492

23. Kokkinons PF., Narayan P., Colleran JA., Pittaras A., Notargiacomo A., Reda D., Papademetriou V. (1995). Effect of Regular Exercise on Blood Pressure and Left Ventricular Hypertrophy in African - American Men With Severe Hypertension. N Engl J Med, 333(22), 1462-7

24. Notoatmodjo. (2005). Metodelogi Penelitian Kesehatan. Jakarta: PT. Rineka Cipta

25. Sugiyono. (2010). Statistika Untuk Penelitian. Bandung: CV Alfabeta. 